\title{
Júri simulado e tempestade cerebral: entendendo implantação da Usina Hidrelétrica de Belo Monte
}

Marcos Marques Formigosa ${ }^{1}$, Miriam Ines Marchi ${ }^{2}$, José Claudio Del Pino ${ }^{3}$, Marli Teresinha Quartieri ${ }^{4}$ ${ }^{1}$ Universidade Federal do Pará - UFPA. Faculdade de Etnodiversidade. Campus Universitário de Altamira. Rua Cel José Porfírio, 2125. Altamira - PA. Brasil. mformigosa@ufpa.br. ${ }^{2}$ Universidade do Vale do Taquari UNIVATES. ${ }^{3}$ Universidade do Vale do Taquari - UNIVATES. ${ }^{4}$ Universidade do Vale do Taquari - UNIVATES.

RESUMO. O ensino de Física ainda encontra muitos entraves na educação básica, principalmente pelas fortes resistências que encontramos dentro das suas metodologias, ainda centralizada no livro didático e na memorização de fórmulas e leis. Este manuscrito tem por objetivo apresentar os resultados das estratégias de ensino Júri Simulado e Tempestade Cerebral desenvolvidas no curso de Licenciatura em Educação do Campo (ênfase em Ciências da Natureza), especificamente na disciplina Fundamentos de Física III em duas turmas do $4^{\circ}$ Período, no interior da Amazônia Paraense. Em uma turma utilizamos a estratégia Tempestade Cerebral, em outra a estratégia foi o Júri Simulado, no conteúdo Eletricidade. As análises foram a partir dos relatos dos alunos da turma e anotações realizadas pelo professor/pesquisador. Essas estratégias desenvolvidas possibilitaram a ruptura dos estereótipos presentes entre os alunos sobre as metodologias utilizadas por seus professores ao ensinarem conteúdos de Física, que pauta-se em aulas tradicionais expositivas, e com as estratégias utilizadas perceberam que as mesmas podem fazer a abordagem dos conteúdos de forma ampliada e, sobretudo os levam a uma compreensão crítica da realidade na qual estão inseridos.

Palavras-chave: Estratégias de Ensino, Júri Simulado, Tempestade Cerebral, Ensino de Física, Educação do Campo. 


\title{
Simulated jury and brain storm: Understanding the implementation of Belo Monte Hydroelectric dam
}

\begin{abstract}
The physics teaching still finds many obstacles in basic education, mainly because of the strong resistance that we find within its methodologies, still centered in the didactic book and the memorization of formulas and laws. This manuscript aims to present the results of the strategies of Simulated Jury and Brain Storm developed in a Countryside Education Degree (emphasis in Natural Sciences), specifically at Fundamentals of Physics III in two classes of the 4th Period, in the countryside Of Paraense Amazon. In one class we used the strategy Cerebral Storm and another strategy was the Simulated Jury, the Electricity content. The analyzes were made based on the reports of the students in the class and notes made by the teacher/researcher. These developed strategies allowed the rupture of the stereotypes presented among the students about the methodologies used by their teachers in teaching Physics contents, which was based on traditional expository classes, and with the strategies used they realized that they can approach the contents of and, above all, led them to a critical reality understanding in which they are inserted.
\end{abstract}

Keywords: Teaching Strategies, Simulated Jury, Brain Storm, Physics Teaching, Countryside Education. 


\section{Jurado simulado y tempestad cerebral: entendiendo la implantación de la Usina Hidroeléctrica de Belo Monte}

RESUMEN: La enseñanza de física todavía encuentra muchos obstáculos en la educación básica, principalmente por las fuertes resistencias que encontramos dentro de sus metodologías, aun centralizada en el libro didáctico y en la memorización de formulas y leyes. Este manuscrito tiene por objetivo presentar los resultados de las estrategias de enseñanza de Jurado Simulado y Tormenta Cerebral desarrolladas en el curso de Licenciatura en Educación del Campo (Énfasis en Ciencias de la Naturaleza) específicamente en la asignatura Fundamentos de Física III en dos clases del $4^{\circ}$ período, en el interior de la Amazonia Paraense. En una clase utilizamos la estrategia tormenta cerebral y la otra estrategia fue el Jurado Simulado a partir en el contenido Electricidad. Los análisis fueron a partir de los relatos de los alumnos de la clase y anotaciones realizadas por el profesor/investigador. Estas estrategias desarrolladas posibilitaron la ruptura de los estereotipos presentes entre los alumnos sobre las metodologías utilizadas por sus profesores al enseñar los contenidos de Física, que se basan en clases tradicionales expositivas, y con las estrategias utilizadas percibieron que las misma pueden hacer el abordaje de los contenidos de forma ampliada y, sobre todo los llevan a una comprensión critica de la realidad en la que están insertados

Palabras clave: Estrategias de Enseñanza, Jurado Simulado, Tormenta Cerebral, Enseñanza de Física, Educación del Campo. 


\section{Introdução}

O ensino de Física no Brasil tem experimentado nas últimas décadas diversas metodologias, mas ainda tendo o livro didático como principal aporte referencial, onde o professor prefere "explicar, ou simplesmente repetir, o que está no livro e dar uma lista de problemas aos alunos" (Moreira, 2000, p. 95), em detrimento de outras metodologias que possam contribuir no processo de ensino e aprendizagem. Não estamos com a pretensão de advogar sobre qual seria a metodologia mais correta para se ensinar Física, mas contribuir para que o ensino desta disciplina na educação básica tenha diferentes dimensões e que seja capaz de levar a uma compreensão de mundo, tornando-se um cidadão contemporâneo, crítico e solidário, conforme recomenda os Parâmetros Curriculares Nacionais (PCN).

Esse debate se faz necessário no âmbito da educação básica. Pois, falar sobre a Física, enquanto disciplina constituinte do currículo escolar, é se reportar a uma disciplina que enfrenta um ensino pautado em conceitos, leis e fórmulas que parecem mais obsoletos e parecem não estabelecer relações com o contexto sociocultural dos sujeitos, dada a forma como seu ensino ocorre nas salas de aula (Camargo \& Nardi, 2003).
É notório que o processo de ensino e aprendizagem, mesmo que tenha apresentado relativas mudanças, ainda pauta-se em conteúdos que privilegia a teoria, a abstração e prima pela resolução de extensas listas de exercícios como única forma de fixação dos conteúdos. Portanto, reduz a Física a uma disciplina a um produto pronto e acabado que precisa ser apenas memorizado e repetido (Brasil, 2002), e que não há necessidade de aprofundar seu estudo, ficando apenas na relação das fórmulas matemáticas atrelados a problemas superficiais.

Esse cenário, muito comum nas salas de aula, sugere que as práticas educativas atuais devem ser (re)pensadas. Buscar por novas possibilidades de intervenção pedagógica para a melhoria do processo de ensino e aprendizagem é emergente e deve estar embasada nos objetivos do ensino de Física na educação básica, conforme recomenda Brasil (2002).

Buscando romper com esses modelos ainda vigentes, há outras metodologias como possibilidades para um ensino de Física exitoso e que podem dar um novo significado ao processo de ensino e aprendizagem dessa disciplina tão importante do currículo escolar. Nessa perspectiva, destacam-se as estratégias de ensino apresentadas por Anastasiou e Alves (2009) e Masetto (2003) entendidas 
como metodologias ativas que podem favorecer a autonomia do aluno, no percurso dos diversos caminhos que ele pode trilhar na busca de uma solução do estudo e/ou da pesquisa por ele desenvolvida.

Para tanto, nos pautamos no seguinte problema de pesquisa: as estratégias de ensino permitem aos sujeitos uma compreensão crítica dos fenômenos naturais e sociais, em uma disciplina escolar que carrega consigo estereótipos que a classificam como uma disciplina difícil, excludente e que poucos tem condições intelectuais de aprender?

Para responder a essa inquietação, nosso objetivo geral foi investigar como as estratégias de ensino empregadas contribuem para favorecer um ensino e aprendizagem de Física. E os objetivos específicos foram: a) conhecer as estratégias de ensino como possibilidade metodológica; b) analisar como as estratégias de ensino podem ser trabalhadas com licenciandos ${ }^{\mathrm{i}}$ no decorrer da formação e c) evidenciar que as estratégias de ensino possuem potencial e devem ser utilizadas no processo de ensino e aprendizagem da disciplina de Física (e outras) quando estes estiverem atuando como docentes.

Este manuscrito, além desta introdução, é constituído por outros tópicos: o referencial teórico sobre as estratégias de ensino, onde apresentamos as duas estratégias que foram utilizadas; em seguida apresentamos o desenvolvimento de cada uma das estratégias nas duas turmas, além das considerações finais e bibliografia.

\section{As estratégias de ensino na sala de aula}

Para além das lógicas internas dos conteúdos desenvolvidos na sala de aula, há necessidade de metodologias que contribuam para sua assimilação facilitando o processo de ensino e aprendizagem do aluno. As estratégias de ensino podem contribuir nesse processo, que vão para além da apreensão de conteúdos, mas que podem agregar valores, mobilizar a construção de sínteses - que estejam diretamente ligadas aos objetivos pretendidos pelo professor despertar interesses pela pesquisa, o que demanda do aluno uma revisão permanente daquilo que ele está estudando (Anastasiou \& Alves, 2009; Mosetto, 2003).

Dessa maneira, as estratégias de ensino podem ser pensadas como uma série de ações pontuais que trabalhadas de forma conjunta entre professor e aluno podem contribuir para atingir objetivos no âmbito da aprendizagem. Para Masetto (2003, p. 88) a “... Estratégia é uma maneira de se decidir sobre um conjunto de 
disposições, ou seja, são os meios que o docente utiliza para facilitar a aprendizagem dos estudantes", e esses meios podem ser viabilizados em qualquer disciplina componente do currículo escolar, a partir de determinados conteúdos.

Diferentemente do jogo, que segue regras e que estas devem ser rigorosamente seguidas, a estratégia de ensino vai se ajustando, mesmo que tenha uma sequência pré-estabelecida, no decorrer de sua ação, pois seu planejamento não pode ser imutável, fixo, mas deve ser construído como algo que vai se encaixando de acordo com o seu andamento e desenvolvimento (Anastasiou \& Alves, 2009).

Masetto (2003) salienta que o professor, além de fazer a escolha correta da estratégia para um determinado objetivo, é necessário que o mesmo tenha estratégias que condizem com o perfil da turma e ou grupo, pois determinadas estratégias podem não surtir efeito dentro dos objetivos traçados dada as especificidades de cada um. Além disso, o autor argumenta que é necessário fazer uma variação no decorrer do curso, para que os alunos sintam-se sempre motivados a participarem e desenvolverem as estratégias, pois a forma de aprender de cada indivíduo lhe é própria.
No caso das estratégias utilizadas, para além do desenvolvimento e assimilação dos conteúdos constituintes das ementas da disciplina Fundamentos de Física III, buscou-se explanar a própria estratégia junto aos licenciandos para que estes pudessem fazer uso das mesmas nas salas de aula, quando estiverem na condição de professores, buscando superar a dicotomia entre teoria e prática, permitindo-lhe ser um sujeito ativo na construção do seu conhecimento, conforme recomenda Gil (2012, apud Mizucano, 1986) quando trata das diferentes formas de abordagens existentes dentro do processo de ensino.

Frente a esse contexto, as estratégias de ensino visam contribuir nessa relação dialógica e aponta para os licenciandos que ensinar Física está para além das fórmulas matemáticas e dos conceitos cartesianos que vem se estendendo dentro das salas de aula, mas como uma disciplina que ajudará a refletir e a entender sobre as diferentes formas de ver e entender o mundo, bem como questionar tais situações.

Mais ainda quando se trata do ensino dessa disciplina nas escolas do campo, que em geral, não possuem professores com formação adequada para a atuação nessa área, dada a própria carência por esse profissional, ou ainda pela infraestrutura que encontramos na escola do campo, que 
não possibilitam o desenvolvimento de um ensino de ciências, inclusive da Física em sua plenitude. E muitas dessas escolas encontram apenas o livro didático como recurso didático para ser trabalhado nas aulas. Dessa forma, é urgente pensar em ações que visem a melhoria no processo de ensino e aprendizagem nas escolas do campo, e as estratégias de ensino podem contribuir nesse processo.

Nesse sentido, optamos por desenvolver as estratégias Júri Simulado e Tempestade Cerebral baseado em Anastasiou e Alves (2009), por acreditarmos que ambas, além de permitirem o trabalho em grupo, desenvolve nos alunos a capacidade de síntese na organização dos seus argumentos individuais e coletivos. Tais afirmativas são corroboradas por Gil (2012, p. 8), quando afirma que há necessidade nesse desenvolvimento: “... Hoje, o que mais interessa é a aquisição de uma mentalidade científica, o desenvolvimento das capacidades de análise, síntese e avaliação, bem como o aprimoramento da imaginação criadora", evidenciando que o uso dessas estratégias pode desenvolver muitos potenciais nos alunos.

A escolha por essas estratégias se deu a partir da necessidade de apresentar aos licenciandos do curso "novos" processos de ensino capazes de estimular os trabalhos individuais e em grupo como forma de estruturar determinadas ideias e conceitos, aguçando o poder de argumentação, criatividade e criticidade que podem contribuir para sua atuação como professores na educação básica. Além disso, essas estratégias não demandam, exclusivamente, por materiais que só podem ser encontrados dentro do espaço escolar, o que contribui muito para ser desenvolvido por eles quando atuarem nas escolas do campo, que, em geral, possuem uma estrutura precarizada, inclusive de material didático. No caso dessas estratégias, acreditamos que os saberes trazidos pelos alunos a partir de suas vivências, sejam necessários e importantes para ajudar a entender determinados conteúdos, considerando que a figura do professor é indispensável nesse processo.

\section{A estratégia de ensino Júri Simulado}

O júri simulado enquanto estratégia de ensino possibilita a abertura para amplos debates de temas/conteúdos que, se abordado por meio de outra estratégia, poderia não alcançar determinado objetivo que fora proposto pelo professor e permitir a introdução de novos diálogos nas aulas de Ciências (ou outra disciplina, como a Física), levando os alunos a desenvolverem 
habilidades na argumentação nas defesas de ideias e tomadas de decisões, conforme aponta Anastasiou e Alves (2009, p. 99): "A estratégia de um júri simulado leva em consideração a possibilidade da realização de inúmeras operações de pensamento, como: defesa de ideias, argumentação, julgamento, tomada de decisões, etc.”. Dessa maneira, nessa estratégia temos a possibilidade de desenvolver nos alunos outras habilidades que estão para além dos conteúdos escolares e isso é indispensável para um professor.

Além disso, permite o trabalho em grupo que, por sua vez, está para além da junção de pessoas, “... mas o desenvolvimento inter e intrapessoal e o estabelecimento de objetivos compartilhados" (Anastasiou \& Alves, 2009, p. 83), além de permitir que os alunos desenvolvam um trabalho em conjunto e coletivo e contribuir para o repensar sobre os discursos que são amplamente levantados nas aulas de Física, conforme apontamos anteriormente. Fazer uso dessa estratégia dentro de um curso de formação de professores, enquanto espaço privilegiado para a introdução de novas práticas e ideias, com o intuito de estabelecer uma relação dialógica entre a prática docente desse professor na educação básica e sua formação.
Segundo Anastasiou e Alves (2009) o Júri Simulado pode ser dividido pelas seguintes personagens: o juiz, o escrivão, a promotoria, a defesa, conselho de sentença e a plenária que podem ser distribuídos entre os alunos conforme os critérios estabelecidos pelo professor em diálogo com a turma. Assim, todos, desde o início, já iniciam a estratégia participando ativamente da sua construção.

\section{A Tempestade Cerebral enquanto estratégia de ensino}

Esta estratégia de ensino, segundo Anastasiou e Alves (2009), pode ser oral e/ou escrita, tem por objetivo explorar as habilidades, potencialidades e criatividade dos alunos e deve ser explanada no início de cada aula, com questionamentos feitos pelo professor sobre um determinado tema que será discutido no decorrer da aula. Mas, Anastasiou e Alves (2009, p. 81) ressaltam que para além da mobilização inicial, essa mesma estratégia pode ser utilizada no decorrer da aula, como forma de diagnóstico daquilo que está sendo trabalho, ou como fechamento de uma aula.

Como todos os alunos são estimulados a falarem sobre o tema inicial, surgem novas ideias que aumentarão o leque de possibilidades dos alunos: "É uma possibilidade de estimular uma nova 
geração de novas ideias de forma espontânea e natural, deixando funcionar a imaginação. Não há certo ou errado. Tudo o que for levantado será considerado, solicitando-se, necessário uma explanação posterior do estudante" (Anastasiou \& Alves, 2009, p. 89), que podem ser retomadas pelo professor (e pelo próprio aluno) no decorrer do andamento das aulas sempre que julgarem necessário.

Ao fazer uso dessa estratégia, o professor permite com que os alunos passem a direcionar um novo olhar para o tema proposto que outrora não tinham se atentado, ampliando seu olhar, inclusive indo, muitas vezes, de encontro com ideias previamente definidas e vivenciadas pelos alunos (Anastasiou \& Alves, 2009). E esse estímulo que os alunos sofrem, a partir dos diferentes olhares, pode desenvolver nos mesmos $\mathrm{o}$ respeito à diversidade e às diferentes formas de ver e conceber o mundo.

A estratégia permite ainda, fazer com que o aluno desenvolva o exercício da escrita, a partir de palavras soltas, que quando sistematizadas de forma coerente e coesa podem gerar frases com conteúdos específicos ou atrelados a significados do contexto sociocultural do aluno. Dessa forma, possibilita ao aluno fixar palavras e/ou frases que surgem no decorrer da construção da estratégia que podem ser exploradas em outros momentos, seja na sala de aula ou em outros espaços.

\section{Procedimentos metodológicos do uso das estratégias nas aulas de Física}

As estratégias de ensino, Júri Simulado e Tempestade Cerebral, foram desenvolvidas no curso de Licenciatura em Educação do Campo (ênfase em Ciências da Natureza) $)^{\text {ii }}$, em funcionamento na Universidade Federal do Pará (UFPA), Campus Universitário de Altamira, com duas turmas do $4^{\circ}$ Período, especificamente na disciplina Fundamentos de Física III. Esse Curso tem uma organização curricular que integra aspectos teóricos e práticos aportados na Pedagogia da Alternância ${ }^{\text {iii }}$ e busca contribuir com a formação de professores para atuação nas escolas do campo, principalmente na área de Ciências, onde as lacunas existentes pela ausência desses profissionais são extensas, conforme já frisamos anteriormente.

A utilização de ambas as estratégias ocorreu a partir do tema Eletricidade: Formas de geração e transmissão e seus impactos na natureza: implicações para a educação ambiental, parte integrante da ementa da disciplina Fundamentos de Física III (carga horária de 60h). Em cada uma das estratégias fizemos uso de $4 \mathrm{~h}$, sendo que para o Júri Simulado foi distribuído em dois dias de aula (com $2 \mathrm{~h}$ 
para cada um dos dias) e a Tempestade Cerebral em apenas um turno. A turma onde desenvolvemos o Júri Simulado é constituída por 34 licenciandos, e na turma onde a Tempestade Cerebral foi utilizada, existem 24 alunos.

A análise dessas estratégias, que visa produzir conhecimento por meio de uma ação educativa, figura-se como pesquisaação, por se tratar, segundo Minayo (1994), de uma investigação social de base empírica, onde pesquisadores e participantes estão interagindo no decorrer do seu desenvolvimento. A pesquisa permitiu interagir com os sujeitos que dela participaram, além de garantir que as estratégias que foram desenvolvidas com as turmas fossem avaliadas e confrontadas com os objetivos previamente traçados.

A pesquisa pautou-se numa abordagem qualitativa por responder, segundo Minayo (1994, p. 21) "a questões muito particulares ... com o universo de significados, motivos, aspirações, crenças, valores e atitudes, o que corresponde a um espaço mais profundo das relações, dos processos e dos fenômenos que não podem ser reduzidos à operacionalização de variáveis". Nesse sentido, dada a subjetividade, imbricada de muitas intervenções, ora por aluno, ora por nós, buscamos os significados em que essas ações implicavam nas relações que eram estabelecidas na sala de aula, por serem estas relações humanas (Minayo, 1994).

Por estarmos emergidos dentro do contexto da estratégia, tivemos contato direto com os sujeitos envolvidos e os dados, registrados no diário de campo, foram analisados no decorrer observação participante:

... A importância dessa técnica reside no fato de podermos captar uma variedade de situações ou fenômenos que não são obtidos por meio de perguntas, uma vez que, observados diretamente na própria realidade, transmite o que há de mais imponderável e evasivo na vida real (Neto, 1994, p. 59-60).

Além disso, os licenciandos foram motivados a fazerem suas considerações de forma verbal e escrita sobre a estratégia, a partir de perguntas feitas por nós sobre a mesma, como parte constituinte da pesquisa-ação. $\mathrm{Na}$ análise dessa avaliação, fizemos uso das iniciais dos nomes dos licenciandos, como forma de manter sua identidade preservada.

Para este manuscrito, faremos a descrição de como cada uma das estratégias ocorreu, para posteriormente apresentar algumas considerações sobre a forma como os licenciandos reagiram à mesma.

\section{O julgamento da implantação de uma hidrelétrica no Rio Xingu}


No primeiro dia, fizemos a apresentação da proposta sobre a estratégia, indagando entre os alunos quais deles já a conheciam e apenas um dos licenciandos manifestou conhecer. Ao descrever como ocorreria, observamos o interesse dos mesmos, que foi ficando mais aguçado quando afirmávamos que a estratégia seria executada por eles, para que quando estivessem exercendo a docência pudessem desenvolver com seus alunos. E tivemos uma licenciando que indagou: "E na aula de Física dá pra fazer isso, professor?", demonstrando claramente que mesmos os alunos de um curso que prima por uma formação diferenciada ainda veem a Física aos moldes apresentados por Moreira (2000) e Brasil (2002).

Feita a motivação inicial para a participação da turma toda na atividade, e como a estratégia se constituía, e ouvindo aos licenciandos, optamos por fazer a divisão dos grupos, por meio de sorteio, que ficou estruturado conforme as recomendações de Anastasiou e Alves (2009). Em seguida, distribuímos o material de apoio desses mesmos autores que explanava a estratégia e fizemos a orientação de cada grupo, explicando o papel de cada um dos grupos, apontando a necessidade de pesquisar informações atualizadas que seriam utilizadas no decorrer do desenvolvimento da atividade. Os licenciandos foram motivados a fazerem uso de vídeos, fotografias, apresentar reportagens de jornais, etc. Disponibilizamos os recursos como data show, caixa de som, computador para que os licenciandos fizessem uso.

No dia seguinte, os alunos chegaram 30 minutos antes do horário estabelecido e fizeram a distribuição das carteiras na sala de aula, da seguinte forma: o Juiz e o Escrivão ficaram à frente da sala, com o Juiz ocupando a mesa do professor e o Escrivão em outra mesa menor ao lado; os grupos da Defesa e Promotoria ficaram de frente, enquanto o Conselho de Sentença ficou ao meio de ambos, um pouco mais recuado. A Plenária ficou ao fundo da sala.

$\mathrm{O}$ argumento posto para ser discutido na estratégia foi a implantação da Usina Hidrelétrica de Belo Monte (UHBM) ${ }^{\text {iv }}$ no rio Xingu. Por termos trabalhados em aulas anteriores sobre as fontes geradoras de energia elétrica, onde apresentamos a hidrelétrica como uma dessas fontes. Optamos por fazer uso desse tema, pois a implantação desse projeto é um fato histórico para os moradores da região, que tem gerado amplo debate nas rodas de conversas dos diversos segmentos sociais, com manifestações favoráveis e contrárias ao projeto. Para a aula, fizemos a simulação de fatos, muitos deles são 
verdadeiros e outros apenas suposição ou interpretação feita pelos alunos a partir das pesquisas por eles realizadas, pois a estratégias de ensino nos permitem fazer uso de situações reais ou simuladas (Berbel, 2011, p. 29).

Nessa estratégia, apresentamos em um quadro síntese, constituído pela sequência de como ela foi desenvolvida na sala de aula. Optamos por deixar as iniciais dos nomes das personagens em maiúsculas, como forma de destacar cada um deles. Ao fazermos a avaliação da estratégia, algumas falas dos alunos foram colocadas entre aspas e itálico, além de colocar apenas as iniciais dos alunos como forma de preservar suas identidades.

Quadro 1: Execução do Júri Simulado.

\section{O JULGAMENTO}

Quando o Juiz entrou na sala, todos os participantes ficaram de pé, a pedido do Escrivão. Ao iniciar o julgamento, o Juiz fez a leitura do seguinte texto para justificar a necessidade daquele momento:

“A geração de energia elétrica é indispensável para o desenvolvimento do país, e a hidroeletricidade é uma das energias ambientalmente mais limpas do planeta, sendo o Brasil um país com ampla bacia hidrográfica e grande parte dela está concentrada na Amazônia, é oportuno que seja implantada nessa região a Usina Hidrelétrica de Belo Monte, que contribuirá para a geração de energia para a região e alavancar o desenvolvimento do país. Todavia, inúmeros problemas socioambientais são apontados por especialistas, como o desemprego, aumento da violência e da prostituição, atingir comunidades tradicionais, inclusive os indígenas. E estamos aqui para julgar se a Usina Hidrelétrica de Belo Monte deve ser implantada no Rio Xingu, após ouvirmos os interessados".

Feita a leitura, o Juiz pediu que todos se sentassem e em seguida disse que a Promotoria iniciaria o debate, com duração máxima de quinze minutos e que o mesmo tempo seria destinado para que a Defesa fizesse uso e apresentasse seus argumentos.

\begin{tabular}{|l|l|}
\hline \multicolumn{1}{|c|}{ A PROMOTORIA } & \multicolumn{1}{c|}{ A DEFESA } \\
\hline - Apresentou um vídeo ${ }^{\mathrm{v}}$ sobre o processo de & - Iniciou com um vídeo ${ }^{\mathrm{vi}}$ mostrando as contribuições \\
funcionamento de uma usina hidrelétrica; & que a UHBM trará não apenas para a região, mas \\
- Arguiu que as propagandas veiculadas nos meios de & para todo o país como emprego; \\
comunicação só apresentam os benefícios que as & - Mostrou que o projeto preservará o meio ambiente \\
hidrelétricas trazem para a população, principalmente & com desenvolvimento sustentável; \\
no que concerne a geração de energia; & - Afirmou que a hidrelétrica é uma fonte de energia \\
- Apresentou slides em PowerPoint em equipamento & limpa; \\
de datashow as desvantagens, apresentando imagens & - Arguir que a água é inesgotável; \\
sobre a implementação de uma usina hidrelétrica; & - Afirmou que a energia ficará mais barata, pois não \\
- Destacou o fluxo migratório, que gerará aumento & será importada de outro local; \\
populacional na cidade, o que acarretará na & - Destacou que o projeto respeitará as comunidades \\
precarização da oferta de serviços essenciais para a & indígenas; \\
\hline
\end{tabular}




população, como a saúde e educação;
- Falou da precarização do trabalho, dado a mão de
obra não qualificada;
- Relacionou a ausência de emprego com o aumento
da violência;
- Falou do impacto ambiental, com grande
mortandade de peixes, dada a mudança no fluxo
natural do rio, além da perda da fauna e da flora;
- Argumentou que a energia não ficará mais barata;
- Arguiu que o objetivo final do projeto é atender aos
grandes centros industriais;
- A água não é fonte inesgotável: e falou dos projetos
relacionados à construção de hidrelétricas na região
Sul e Sudeste do país que já sofrem com a ausência
de água em determinados períodos do ano;
- Ressaltou que há outras fontes de geração de
energia mais baratas e mais limpas como a eólica e a
solar, e que o país tem grande potencial para investir
nessas duas fontes.

- Afirmou que todas as famílias que forem remanejadas de seus locais de origem seriam assistidas pelo projeto, com construção de casas e indenização financeira pelos imóveis que seriam demolidos para prevenir possíveis alagamentos e inundações;

Apresentou uma testemunha ${ }^{\text {vii }}$ que discorreu sobre a importância do projeto que trará desenvolvimento para a região, gerando emprego e renda e movimentará a economia local, e produzirá energia barata, já que será produzida por aqui mesmo.

Ao finalizar os debates o Juiz deu um recesso a todos, enquanto o Conselho de Sentença se reuniu para dar seu voto. Feito isso, o julgamento teve seu retorno e, a pedido do Juiz, foi feita a leitura pelo Escrivão, do que ocorrera naquela manhã de julgamento.

Em seguida, o Conselho de Sentença fez a leitura de seu parecer sobre o julgamento:

“Considerando os argumentos e debates amplamente feitos pela Defesa e Promotoria em torno da implantação da UHBM, e levando em consideração a necessidade de ampliação dos investimentos em áreas estratégias para o desenvolvimento do país, a partir da geração de emprego local, aumento na produção de energia elétrica, preocupação com o meio ambiente e as comunidades tradicionais, inclusive os indígenas, apresentado dentro da exposição da Defesa por meio das condicionantes compensatórias, este Conselho é favorável a execução do Projeto Belo Monte".

O juiz deu por encerrado o julgamento, acatando o parecer do Conselho de Sentença.

Fonte: Elaborado pelos autores.

\section{Nossas impressões sobre a Promotoria}

A forma como apresentaram as desvantagens estavam divididas em tópicos, a saber: ambiental, social, educacional. Mas, os licenciados optaram por dar ênfase aos os impactos sociais e ambientais, por eles descritos como sendo impactos socioambientais.

Ao lado de cada uma das explanações feitas pelos licenciandos, eram apresentadas reportagens de jornais sobre a implantação de grandes projetos, o que demonstrava que os mesmos tinham feitos 
as pesquisas na internet $\mathrm{e}$ em sites confiáveis. A cada tópico apresentado, os membros do grupo que representava a defesa, sussurravam entre si e faziam anotações sobre o mesmo, como forma de ir respondendo cada um dos tópicos quando lhe fosse oportunizado o momento.

O tópico que chamou atenção dos alunos foi sobre os impactos ambientais que serão causados pelo projeto, considerando que a mesma seria implantada em uma das regiões com maior biodiversidade do planeta, além de estar próxima a um dos mais importantes parques indígenas do Brasil, o Parques Indígena do Xingu. A devastação da flora e da fauna serão incomensuráveis, além da ruptura que essas comunidades tradicionais terão com seus espaços em decorrência do remanejamento de comunidades inteiras por conta das possibilidades de inundação quando a usina estiver em pleno funcionamento.

Quando a defesa afirmou que haverá respeita com as comunidades indígenas, a promotoria fez um protesto, acatado pelo juiz. Justificou que ao considerar apenas as comunidades indígenas livres dos impactos, o projeto não leva em consideração a existência de outras comunidades tradicionais que ocupam as margens do Rio Xingu, como se os mesmos pudessem ser removidos dos seus lugares que já é ocupado por gerações, o que ocasionará uma ruptura com sua identidade e cultura.

\section{Nossas impressões sobre a defesa}

Ao contrário da promotoria, a defesa optou por fazer uma explanação mais geral sobre o projeto. Não deu ênfase aos tópicos como fizera a promotoria no decorrer da exposição. Dessa maneira, ficou claro que não houve uma preocupação por parte deste grupo em ir sistematizando as informações que fora apresentado pela promotoria, o que poderia facilitar mais ainda a explanação e a compreensão por parte de quem estava participando da atividade.

A testemunha foi o elemento diferenciado que fora apresentado pela defesa, inclusive com as vestimentas características do que seria um ribeirinho, o que contribuiu para o debate. Suas afirmativas fizeram com que os participantes pudessem refletir sobre o olhar que o sujeito local teria para o grande projeto que estava em discussão.

Nessas trocas de informações mediadas pelos dois grupos, os licenciandos que faziam parte da plenária, iam anotando as informações discutidas, para que ao final do julgamento pudessem manifestar, por escrito, qual seria o posicionamento a ser tomado, caso fosse 
ele o juiz que estivesse presidindo $\mathrm{o}$ julgamento. Por conta disso, era notório o empenho dos mesmos, ficando atento às falas e apresentação das imagens e/ou vídeos que eram apresentados por cada um dos grupos envolvidos diretamente no julgamento.

Ao avaliarmos a estratégia, os alunos argumentaram que a mesma lhes deixou "livres" para desenvolverem seus argumentos de acordo com a compreensão daquilo que pesquisaram. Puderam desenvolver uma sequência de argumentações que dependia muito de como outro ponto de vista era posto, considerando que existiam dois grupos que tinham posicionamentos contraditórios.

Professor, foi muito boa a atividade porque, diferente de outros, como o seminário, em que a gente fica receoso de fazer certas perguntas para o grupo, ... aqui a gente pode externar nosso ponto de vista sobre um assunto sem constranger ninguém. (J.B.M.).

Esse argumento é salutar, pois, muitas vezes os alunos deixam de fazer perguntas ao colega para não o deixar em situação embaraçosa junto ao professor ou aos colegas da turma, principalmente quando se trata da exposição de um trabalho, fazendo com que as atividades, como o seminário fiquem apenas na exposição oral por parte dos alunos, sem nenhum diálogo deste com a turma, algo que não ocorre no Júri Simulado.

Outro licenciando arguiu, que pelo fato de ter sido feito o sorteio, teve que defender algo que não concorda:

\begin{abstract}
Quando o professor fez o sorteio e eu caí no grupo da defesa eu não gostei, por que sou contra a Belo Monte. Isso foi o mais difícil pra mim: fazer uma fala favorável a algo que pessoalmente sou totalmente contra, mas tinha que defender a ideia, e isso me fez me colocar no lugar do outro, e ver como o outro pensa a respeito de determinado assunto (L.M.D).
\end{abstract}

Pelas falas do licenciando, observamos que a atividade lhe fez pensar sobre a sensibilidade que precisa ser desenvolvida para lhe dar com situações contrárias àquilo que gostaria de desenvolver, mais ainda em se colocar no lugar do outro, conhecer os argumentos dos outros para só então se posicionar a respeito: "Júri simulado numa aula de Física. Quando falei isso em casa, meu pai disse que o nosso curso é mesmo diferente" (A.F.S).

Posto isso, percebemos o quão a atividade foi significativa para a turma toda e como que novas estratégias se forem bem desenvolvidas podem contribuir para um novo olhar que brota nas novas formas de ensinar e de aprender que vão sendo construídas no interior da sala de aula e que tais formas podem romper com 
estereótipos enraizados no contexto escolar.

\section{A UHBM como uma tempestade na Amazônia}

A propósito desse título, discorremos com o intuito de fazer uma analogia à estratégia denominada Tempestade

Cerebral, por esta permitir que as inúmeras ideias prévias sejam apresentadas sobre um determinado tema (Anastasiou e Alves, 2009), algo não diferente com a implantação da UHBM, dadas as suas diferentes leituras favoráveis e contrárias que acompanham o desenrolar desse projeto na região.

Assim como a estratégia anterior, fizemos a motivação inicial para os licenciandos sobre a proposta da atividade. Os alunos foram divididos em grupo de três pessoas, por meio de divisão feita por eles mesmo, totalizando 8 grupos. A partir da palavra eletricidade, fixada por nós em um papel A4 no centro do quadro, cada licenciando deveria escrever em outro papel uma única palavra que remetesse à palavra em destaque, conforme imagem 1 abaixo:

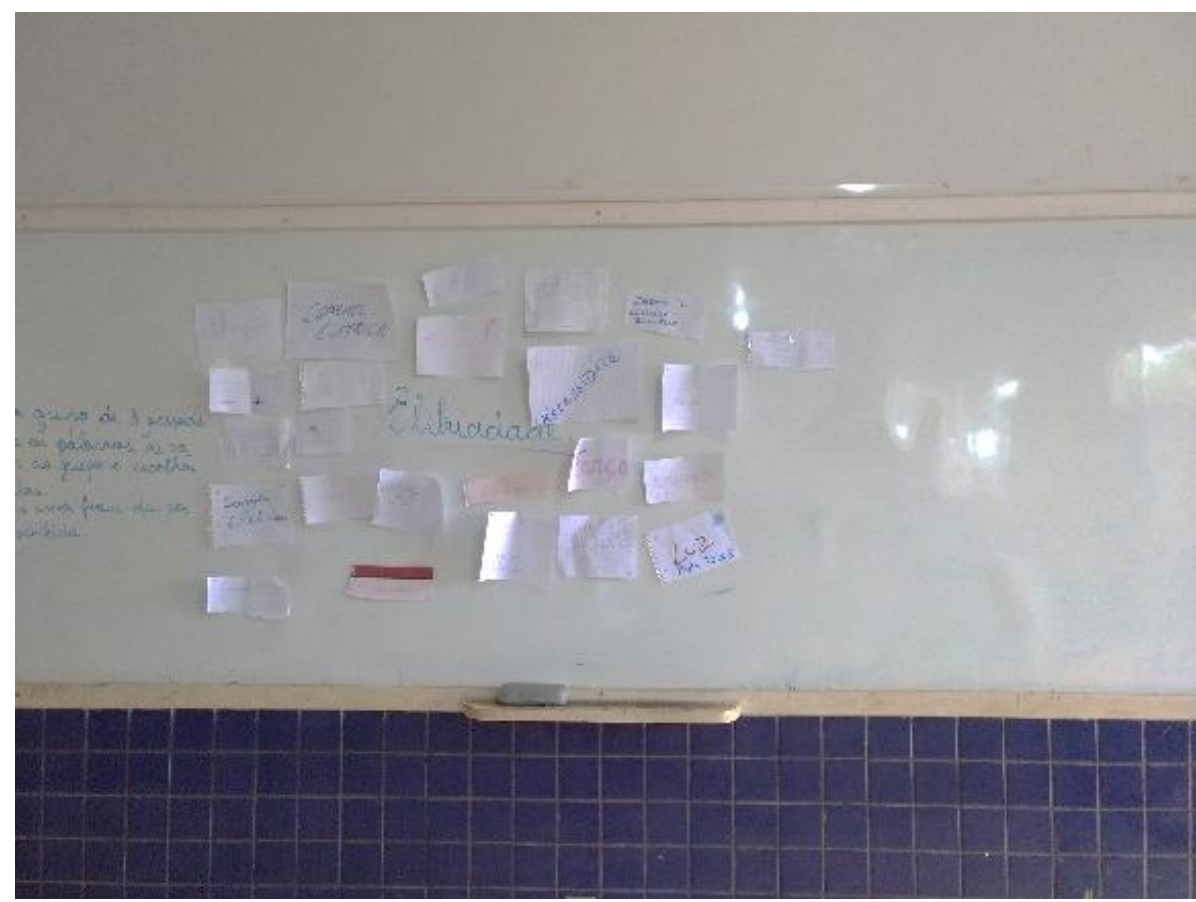

Fonte: Arquivo pessoal.

Diversas palavras, conforme pelos licenciandos que entre si discutiram observamos na imagem 1, foram feitas e, conforme nossa recomendação, dentro 
do grupo não podia ter palavras repetidas. Cada um dos licenciandos se dirigiu ao quadro e afixou sua palavra de forma aleatória. E após esse momento, foi possível notar que algumas palavras se repetiram, mas foram geradas por grupos diferentes. Palavras como corrente elétrica, tensão, força, energia, luz, tecnologia, etc. foram mais recorrentes entre os grupos. Mas, dentre elas encontramos uma que chamou a atenção: a palavra água. Quando apontada por nós, percebemos que causou estranheza e incompreensão, num primeiro momento para alguns licenciandos.

Conforme recomenda Berbel (2011), indagamos aos licenciandos, na perspectiva de acolher seu pensamento, buscando o desenvolvimento motivacional: por que falar de água quando nossa palavra chave é eletricidade? Qual a relação que pode existir entre ambas as palavras? Anastasiou e Alves (2009, p. 90) chamam a atenção para quando esse tipo de situação ocorre ao afirmar que palavras como essa “... nos mostra a riqueza da possibilidade de diferentes conexões, pontos de chegada e de partida que os participantes trazem ao contexto ...".

O licenciando do grupo que escreveu a palavra se manifestou dizendo: "Professor, a água é capaz de gerar eletricidade, por conta da força que ela tem, por isso a Belo Monte foi construída aqui no Xingu, porque possui muita água” (C.S.P.). As falas iniciais do licenciando apontam para um conhecimento prévio que possuía sobre a relação da geração de energia elétrica a partir da força da água existente no rio. Para Anastasiou e Alves (2009, p. 89-90), "Esse simples exemplo nos mostra a riqueza da possibilidade de diferentes conexões, pontos de chegada e de partida que os participantes trazem ao contexto". Por mais que não tivesse a definição clara do que estava afirmando, o licenciando estava fazendo uma relação direta da energia cinética e a geração de energia elétrica.

$\mathrm{Na}$ sequência, outro licenciando argumentou: 'E mesmo 'fazendo' energia aqui, professor, a gente paga muito caro, parece que a conta de luz só aumenta..." (M.L.D.C). A afirmativa do licenciando traz à tona as diversas leituras e interpretações em torno da UHBM, que faz com que os demais colegas de turma queiram discutir outros assuntos relacionados ao projeto de Belo Monte, o que nos permite estreitar a relação de um conteúdo da Física com problemas vivenciados por eles. Dessa maneira, buscamos mediar esse diálogo, na perspectiva de apontar que esta disciplina, para além das fórmulas e leis, e no caso específico do conteúdo eletricidade, que permite conhecer as diferentes formas de 
geração e transmissão de energia, pode contribuir na reflexão sobre como esses processos, imbricados nas suas formas implicam diretamente na vida dos sujeitos que são diretamente impactados, tanto no aspecto ambiental, como social.

Posto isso, começaram a surgir outros argumentos em torno da implantação da UHBM como a prostituição, aumento do trabalho infantil, desemprego, violência, aumento do custo de vida, escassez de peixes nos rios da região. Apoiados nessas afirmativas dos licenciandos, motivamos que criassem frases a partir das três palavras formadas em cada grupo e socializassem com a turma. Para essa construção, os grupos poderiam complementar com outras palavras que julgassem necessárias para que a frase criada tivesse coesão e sentido.

Muitos grupos construíram as frases com definição do que seria uma corrente elétrica, tensão elétrica, transmissão de energia, geração de energia, fontes de energia, buscando pesquisar na internet por meio do celular. Outros, por sua vez, já deram ênfases nos impactos ambientais, impactos sociais e etc. que são causados pelas fontes de energias, como os que apontamos anteriormente. Vale ressaltar, que ao contrário da turma anterior, onde desenvolvemos o Júri Simulado, não tínhamos trabalhado com os alunos o conteúdo eletricidade, ou seja, não tínhamos apresentado a eles o conteúdo sobre as fontes geradoras de energia elétrica, dentre eles a hidrelétrica.

Dentre as muitas frases por eles criadas, o grupo que escreveu as palavras água e energia, demonstrando que conseguiu assimilar a proposta feita, construiu a seguinte frase. "A água é fonte de tudo, inclusive da geração de energia elétrica".

A proposta foi muito bem absorvida pelos licenciandos que puderam fazer $\mathrm{o}$ exercício da discussão coletiva e individual, onde percebemos um amplo debate e defesa de ideias pessoais e coletivas, conforme observamos nas falas registradas pelos licenciandos: "Professor a atividade foi muito produtiva, partiu de uma palavra central que desencadeou vários outros subtemas, e a partir disso deu-se o andamento da aula de Física (M.A.S.). Outro licenciando disse: "Essa atividade foi bastante produtiva, pois trabalhamos em um meio coletivo, onde a turma toda participou expondo suas palavras e frases dando o conceito de coisas a partir da palavra central, parecia que nem era aula de Física” (R.C.A.)

Como é possível observar, os licenciandos acolheram e desenvolveram a atividade com muito entusiasmo e a desenvolveram de forma exitosa. Nesse 
sentido, ressaltamos aqui as falas dos licenciandos quando se trata do fato de essa estratégia ter sido desenvolvida durante uma aula de Física. Pois, a mesmas vai de encontro com outras aulas de Física que esses mesmos licenciandos comumente tiveram na educação básica que primava pela decoração de fórmulas, leis e respostas corretas. Moreira e Massoni (2016, p. 5) argumentam que "Os alunos devem ser ensinados a pensar, a questionar, a argumentar cientificamente ao invés de ficar decorando fórmulas e definições", mesmo que para isso o professor tenha que repensar muito das suas práticas.

Além de ressaltar a possibilidade de o professor reconhecer os conhecimentos prévios dos alunos, e que esses conhecimentos podem ajudar outro colega que não conhece o conteúdo, outro licenciando afirmou que fará uso da estratégia quando estiver atuando como docente:

A atividade possibilita ao professor distinguir o que o aluno tem ideia sobre um determinado tema e ao mesmo tempo a ideia dos colegas servem para os quais ainda não tem noção do que está sendo falado se aproprie do assunto. Eu vou fazer uso quando tiver dando aula (A.M.P.S, grifos nossos).

É possível observarmos o quão importante é para os licenciandos conhecerem novas propostas metodológicas que podem contribuir no seu desenvolvimento profissional e que quando são imersos em outras possibilidades, demonstram que estas influenciam diretamente na forma de lidar com determinados conteúdos ou disciplinas e que por ter sido muito exitosa contribuem para o repensar sobre a atuação no futuro.

O engajamento do aluno em relação a
novas aprendizagens, pela
compreensão, pela escolha e pelo
interesse, é condição essencial para
ampliar suas possibilidades de
exercitar a liberdade e a autonomia
na tomada de decisões em diferentes
momentos do processo que vivencia,
preparando-se para o exercício
profissional futuro ... (Berbel, 2011,
p. 29).

Considerando que estes licenciandos fazem e farão parte de vários processos educativos e demandam pelo “... desenvolvimento de novas habilidades, na modificação de atitudes e comportamentos e na busca de novos significados nas pessoas, nas coisas e nos fatos" (Gil, 2012, p. 6), acreditamos que tais estratégias são muito importantes na construção desse processo.

\section{Considerações finais}

As estratégias desenvolvidas nas turmas de graduação nos permitiram perceber o quanto que os cursos de graduação são deficientes de novas 
metodologias que precisam ser desenvolvidas em sala de aula. Romper com esse modelo que está enraizado, principalmente em disciplinas que ainda tem no livro didático seu maior aporte, como é o caso da Física, é um grande desafio.

O Júri Simulado e a Tempestade Cerebral permitiram vislumbrar outras possibilidades que estes licenciandos podem desenvolver quando estiverem no exercício docente, além de motivá-los a busca pela pesquisa. Pois, em geral, encontramos um modelo de educação que prima pela discussão de conteúdos trazidos pelo professor onde, sua aprendizagem fica limitada àquilo que é discutido em poucas horas na sala de aula. E essa limitação pode ser superada quando os alunos são instigados a desenvolverem pesquisas, sejam capazes de ter um novo olhar para um determinado tema/conteúdo, ou ainda que tal tema/conteúdo tem outras possibilidades de correlação com outros temas e outras aplicabilidades que o professor não conseguiria explanar dentro da sala de aula.

Assim, essas estratégias possibilitaram a ruptura dos estereótipos presentes entre os alunos sobre as metodologias utilizadas por seus professores ao ensinarem conteúdos de Física, que pautavam-se em aulas tradicionais expositivas, e com as estratégias utilizadas perceberam que as mesmas podem fazer a abordagem dos conteúdos de forma ampliada e, sobretudo os levam a uma compreensão crítica dos fenômenos naturais e sociais na qual estão inseridos, inclusive por meio da disciplina de Física.

\section{Referências}

Anastasiou, L. G. C., \& Alves, L. P. (2009). Estratégias de ensinagem. In Anastasiou, L. G. C., \& Alves, L. P (Orgs). Processos de ensinagem na Universidade: pressupostos para estratégias de trabalho em aula (pp. 75-107). Joinville: Univille.

Barreto, A. L. V., \& Miltão, M. S. (2013). A pedagogia da alternância: o contexto das EFAS e as teorias e leis gerais da física. In Anais do XX Simpósio Nacional de Ensino de Física - SNEF 2013 (pp. 1-6). São Paulo, SP.

Berbel, N. A. N. (2011). As metodologias ativas e a promoção da autonomia de estudantes. Semina: Ciências Sociais e Humanas, 32(1), 25-40.

Brasil. (2002). Ministério da Educação. Secretaria da Educação Média e Tecnológica. Parâmetros Curriculares Nacionais + $(\mathrm{PCN}+)$ - Ciências da Natureza e suas Tecnologias. Brasília: MEC.

Camargo, S., \& Nardi, R. (2003). Formação de professores de Física: os estágios supervisionados como fonte de pesquisa sobre a prática de ensino. Revista Brasileira de Pesquisa em Educação em Ciências, 3(3), 34-55. 
Gil, A. C. (2012). Didática do ensino superior. São Paulo: Atlas.

Masetto, M. T. (2003). Competência pedagógica do professor universitário. São Paulo, SP: Summus.

Minayo, M. C. S. (1994). Ciências, técnica e arte: o desafio da pesquisa Social. In Minayo. M. C. S. (Org.). Pesquisa social: teoria, método e criatividade (pp. 9-29). Petrópolis: Vozes.

Moreira, M. A. (2000). Ensino de Física no Brasil: Retrospectiva e Perspectivas. Revista Brasileira de Ensino de Física, 22(1), 94-99.

Moreira, M. A., \& Massoni, N. T. (2016). Interfaces entre visões epistemológicas e ensino de Ciências. Ensino, Saúde $e$ Ambiente, 9(1), 1-32.

Neto, O. C. (1994). O trabalho de campo como descoberta e criação. In Minayo. M. C. S. (Org.). Pesquisa social: teoria, método e criatividade (pp. 51-66). Petrópolis: Vozes.

Resolução no 4.703 (2015, 19 de agosto). Aprova o Projeto Pedagógico do Curso de Licenciatura em Educação do Campo, de interesse do Campus Universitário de Altamira Belém, PA. Recuperado de: http://www.ufpa.br/sege/boletim_interno/d ownloads/resolucoes/consepe/2015/4703\% 20PPC $\% 20$ Educa\%C3\%A7\%C3\%A3o\%2 0do\%20Campo\%20Altamira.pdf.

Vieira, R. D., Melo, V. F., \& Bernardo, J. R. (2014). O Júri simulado como recurso didático para promover argumentações na formação de professores de Física: o problema do "gato". Revista Ensaio, 16(3), 203-225. alunos do curso de Licenciatura em Educação do Campo, e não sofrerá modificação quando tratarmos de alunos de forma geral.

ii $\mathrm{O}$ curso, segundo seu PPC, habilita os egressos a atuarem nos anos finais do Ensino Fundamental com a disciplina de Ciências e no Ensino Médio com as disciplinas de Biologia, Química e Física.

iii Processos formativos alternados entre Tempo Universidade (TU) e no Tempo Comunidade (TC), entendidos como espaços que se inter-relacionam, a partir dos contextos socioculturais numa relação dialógica permanente.

iv A usina hidrelétrica de Belo Monte implantada às margens do rio Xingu (PA), surge ainda no ano de 1975, ainda no governo militar e foi amplamente defendido pelos governos Lula-Dilma, tendo o início das obras no ano de 2011. A obra atinge muitos municípios da região do Xingu e da Transamazônica, onde esses licenciandos residem.

v Como funciona uma usina hidrelétrica? Disponível em: https://www.youtube.com/watch?v=iYPMZamqSH 4 Acesso em: 20/02/2017.

${ }^{\text {vi }}$ UHE Belo Monte - Apresentação. Disponível em:

<https://www.youtube.com/watch?v=216bIsdTbE $>$. Acesso em: 20/02/2017.

vii Anastisou e Alves (2009) não mencionam essa personagem diretamente, mas na interpretação dos alunos havia a necessidade de ter a pessoa da testemunha, pois segundo eles, não há julgamento sem essa personagem.
Recebido em: 13/07/2017 Aprovado em: 18/08/2017 Publicado em: 13/12/2017

${ }^{\mathrm{i}}$ No decorrer do manuscrito faremos uso do termo licenciando ou licenciandos, ao tratarmos dos 


\section{Como citar este artigo / How to cite this article /} Como citar este artículo:

APA:

Formigosa, M. M., Marchi, M. I., Del Pino, J. C., \& Quartieri, M. T. (2017). Júri simulado e tempestade cerebral: entendendo a implantação da Usina Hidrelétrica de Belo Monte. Rev. Bras. Educ. Camp., 2(3), 899-920. DOI: http://dx.doi.org/10.20873/uft.2525-

$\underline{4863.2017 \mathrm{v} 2 \mathrm{n} 3 \mathrm{p} 899}$

ABNT:

FORMIGOSA, M. M.; MARCHI, M. I.; DEL PINO, J. C.; QUARTIERI, M. T. Júri simulado e tempestade cerebral: entendendo a implantação da Usina Hidrelétrica de Belo Monte. Rev. Bras. Educ. Camp., Tocantinópolis, v. 2, n. 3, p. 899-920, 2017. DOI: $\quad$ http://dx.doi.org/10.20873/uft.2525$\underline{4863.2017 \mathrm{v} 2 \mathrm{n} 3 \mathrm{p} 899}$

\title{
ORCID
}

\author{
Marcos Marques Formigosa \\ iD http://orcid.org/0000-0001-6279-1459
}

Miriam Ines Marchi

(iD) http://orcid.org/0000-0003-2546-7072

José Claudio Del Pino

http://orcid.org/0000-0002-8321-9774

Marli Teresinha Quartieri

http://orcid.org/0000-0002-9621-3830 